\title{
Curious teachers, create curious learners and great historians
}

Sarah Whitehouse, * University of the West of England(UWE), Bristol. England Email:

Sarah.Whitehouse@uwe.ac.uk

Karan Vickers-Hulse, UWE Bristol, England

Jane Carter, UWE Bristol, Bristol, England

\begin{abstract}
Engel (2011) stated that curiosity should be cultivated in our schools as it is intrinsic to children's development. However, this is often absent from classrooms. In this paper we aim to explore some of the factors that have led to a lack of curiosity in today's classrooms by identifying the impact of rapid policy and curriculum change. We will then justify the importance of creative teaching to develop curiosity, not only in children but also in their teachers - curious teachers develop curious learners. We will conclude by sharing some case studies to illustrate how curiosity can be developed using history lessons as a platform.
\end{abstract}

Key Words: teaching history; curiosity; controversial issues; policy and practice; children's voices; enquiry

\section{Introduction}

Piaget (1950) and Kagan (1972) emphasised decades ago that children's development is spurred by their efforts to understand the unknown. Curiosity as a phenomenon has long been embedded in many curriculum subjects, one of these being history. We have fond memories of history being taught in a way that fired our imaginations and encouraged us to ask questions (how did the Egyptians remove the brains?) and develop curiosity. However, education and teaching as a profession have changed significantly since Kagan and Piaget made their claims. In England, along with many other jurisdictions in the world, we have gone through and are still within a culture of professional accountability, performance management and the academicisation of schools. Day (2002) discusses how education reform and policy implementation have evolved from a larger ideological debate surrounding public services in general. New limits were placed on teacher autonomy from the mid-70s; at that time Her Majesty's Inspectors (HMI) were a group of ex-heads and advisors who were tasked with inspecting schools and monitoring effectiveness and LEAs had more power over curriculum content and delivery. Words such as value added, performativity and professional accountability were not yet common terms. Today's picture is very different, with the words progress, accountable, standards and performance being at the front of teachers' minds. Whitty (2002) discusses the idea that the teaching profession is under the microscope and that teachers, as a profession, are now bound more than ever by policy, performance management and accountability. Singh, Heimans and 
Glasswell (2014 p. 833) argue that despite the theorising of a dominant neo-liberally driven performative culture, everyday school practices do not corroborate this view because teachers' base practice on their values which do not in fact change much, despite policy. This paper aims to explore the development of curiosity and the significant impact that policy changes in England have had on restricting the conditions in which teachers work and created a culture of compliance rather than autonomy (Bullock and Thomas, 1997).

\section{Impact of policy}

Ball (2008) discusses the two inevitabilities of policy: that behind all policy lie values and beliefs as well as hidden stories and that behind the production of all policy there will be inevitable outcomes, which are intended and unintended. Is it possible to develop creativity and curiosity in the current climate? The Education Reform Act (HMSO 1988) is a pivotal moment for change in education and the teaching profession. It put into place the steering forms of marketisation and led to the introduction of performance related funding and accountability. Educationalists fell more in line with the private sector and cultures and institutional regulations were introduced, which led to the culture of performativity in education (Ball, 1997). The gap between education policy makers and policy users seems to be widening. McLaughin (1991), cited in Ball (1997), talked about two types of change that evolve in education. On the one hand: colonisation change where fundamental core values are changed and practitioners embed messages and therefore, change their practice. On the other hand there is reorientation change, terminology is changed but values remain; practitioners may be going through the motions and performing expected tasks and behaviours but their ideology of education and their belief system is static.

Therefore, it is difficult for teachers to find their place within a shifting educational context but also very difficult for there to be a national shift in behaviours and attitudes to teaching. Changes in policy are often rapid but a change in attitudes occurs much more slowly. O'Connor (2008) highlights the fact that the current policy climate is quick to judge professional standards and yet fails to recognise the emotional and empathic skills that are essential for fostering curiosity in the classroom. Whilst the Teachers' Standards (Department for Education 2013) tell practitioners to teach good lessons, make accurate assessments and meet the needs of all learners, they do not support practitioners in addressing children's emotional needs and embedding the skills necessary to develop as curious, questioning individuals. 
Helsby (1995) believes that teachers have been judged not only on what they do but also on who they are. Policy makers make a judgement about a teacher's values and beliefs as well as skills, attitudes and knowledge (Wilkins, 2011). Giddens (1991) relates this shift in expectations of teacher professionalism to a parallel shift in society and culture, which he refers to as 'high modernity'. The idea of trust in our daily lives has changed; it is now less personalised and is bound by ever shifting policy, procedure and systems. This leads to a high level of challenge in identifying 'self' and developing 'ontological security' (Giddens, 1991 p.36), even more so in the case of teachers who often have to reconsider their beliefs, values and ambitions at frequent points in their careers. Teachers may start their careers as professionals who develop, hone and instil skills such as awe, wonder and curiosity but how easy is this to maintain in a constantly shifting climate of change?

Teachers are now bound by professional standards and held accountable to Teachers' Standards (2013) and policy. Striving for uniformity and conformity could threaten the teachers' process of forming a culture of curiosity in their classrooms and fostering creativity in the pupils they teach (Beijaard, Meijer and Verloop, 2003). How can teachers adhere to a strict set of guidelines, such as those outlined in the national curriculum and the Teachers' Standards and still develop children's ability to question, wonder and be inspired? The tensions between research into what 'good' teaching and learning looks like and what appears in policy documentation are not necessarily the same. Woods and Jeffrey (2002) state there has almost been a dissolution of the human element of good teaching, with a renewed focus on competencies; there is the constant idea that what went before was not right and that 'now we need to do it this way'. Hargreaves (1994) thinks that teachers are almost trapped in a 'persona of perfection' - being asked to constantly change ideas, approaches and philosophies that may contradict personal beliefs, which implies that teachers are always striving for something that is impossible to achieve.

Prior to the introduction of the first incarnation of the national curriculum (HMSO, 1988) teachers raised concerns about the impact on the hidden elements of teaching; those skills that are taught which are not subject based, such as empathy, curiosity, awe and wonder. In the next part of this paper, we will hone in on one of these elements, curiosity, and look at how the constantly changing goalposts of the current policy climate have impacted on this.

\section{Curriculum}


The (not so new) National Curriculum (2013) sets out, as one of its overarching aims, to introduce 'pupils to the best that has been thought and said; and...engender an appreciation of human creativity and achievement.' This seems like a very noble and ambitious goal although one that seems a little problematic. What are the 'best thoughts' and according to whom; what were the best things 'said'; is all human creativity something that should be appreciated; what do we consider to be achievements; the statement suggests that all the best thoughts and sayings have been thought and said - what about our own thoughts and utterances now? Von Stumm et al. (2011) would argue that such questions are the indicators of 'intellectual curiosity' and as such are the hallmarks of a 'hungry mind'. They argue such traits are predictors of academic achievement. Curiosity then is perhaps something that needs to be taught, encouraged and developed, in teachers as well as in the children they teach. Engel $(2011,625)$ argued that curiosity was 'intrinsic to children's development' and she cites Piaget's (1969) definition of curiosity as 'the urge to explain the unexpected'. Kagan (1972) described curiosity as the 'need to resolve uncertainty'. Engel $(2011,627)$ suggests that curiosity is simply 'the urge to know more.'

The Early Years Foundation Stage Curriculum (DfE, 2017) seems to locate curiosity as an essential element of early learning, stating that there is a need to ignite 'children's curiosity and enthusiasm for learning'. This, it is claimed, enables children to build 'their capacity to learn, form relationships and thrive'. The National Curriculum (DfE, 2013) mentions curiosity six times: in relation to curiosity and enjoyment in maths (page 99), in relation to excitement and curiosity of natural phenomena in science (page 144), in geography in relation to fascination and curiosity about the world and its people (page 184). in relation to languages (page 193), in history in relation to curiosity about the past (page 188) and it is also a word in the Year 5 / 6 statutory spelling list as a word to learn to spell.

If curiosity is both central to learning and to the National Curricula for Early Years and Key Stages 1 and 2, then perhaps it is something that should be a prominent feature of Initial Teacher Education Programmes and should feature on all teachers' schemes of work and planning proformas, the Teachers' Standards (2013) clearly state that in standard 4 that teachers should "promote a love of learning and children's intellectual curiosity" therefore teaches need to take account of this in their planning..Curiosity is rarely identified in this way and there is a growing dominance of the discourse of direct instruction (Coe et al. 2014) that does not mention curiosity. There is a paradox emerging 
from government where on the one hand there is a curriculum that has curiosity as an aim for many curriculum subjects and yet an apparent privileging of teaching approaches that bypass children's curious questions in order to transmit the required knowledge and skills so children are 'test ready'. The teaching of reading highlights this debate, with one view of the teaching of early reading dominating. This view requires a transmission of knowledge to enable children to 'break the code' and focuses on this above children's agency, volition and curiosity as learner readers. Moss (2017) suggests that the primary assessment processes have exacerbated this process with the tools of assessment being used to replace the curriculum. The testing regime narrows the curriculum and so focuses on mathematics and English. The curriculum for mathematics and is English is then further narrowed, with a focus on only those elements that are tested. With these demands being placed on teachers it is possible they may lose the will to develop and nurture curiosity if it means spending time away from the easy gains of direct instruction for test preparation.

What this paper will argue is that curiosity is at the heart of learning. It is also, by definition, at the heart of success in testing as well as in developing children as engaged, independent, problem-solving citizens, which in turn further supports academic achievement. Engel $(2011,628)$ makes this point rather succinctly: 'When children are curious, they learn. It turns out that curiosity in school is not merely a nicety but a necessity.' We all have heard the toddler in the park or supermarket doggedly asking the adult 'why?' We hear the adult's initial explanations, detailed, clear and explicit but as the 'why' question is repeated over and over, the explanations become increasingly exasperated, with an 'It just is!' retort as the final marker of this conversation. This curiosity 'dance' is the hallmark of a young and enquiring mind. However, when children arrive in school Tizard and Hughes (1984) found that the number of questions children asked dropped from an average of 26 per hour to 2 per hour. Engel's (2011) research mirrored this; she looked for 'curious episodes' which she identified as where a child asked a question or 'tinkered' with or opened something. She found that, in a class of 22 children aged 10 to11, curiosity was evident less than 'once in each two hour period'. If we align curiosity with learning, then children's propensity for learning may also be being suppressed or decreased.

\section{Developing curiosity in history}


History can provide the ideal subject setting for teachers to begin to address these issues. If they can be addressed in history teaching and learning then the principles and practices can be applied across the curriculum. Engels (2011) identifies some useful starting points in her article and these have underpinned some of the discussions and case studies below.

1. Understanding what interests children and using this to manipulate what has to be taught and to present children with objects, ideas and concepts that will ignite an interest.

2. Question raising - establishing learning environments and contexts for learning that both enable children to ask questions but also provide time to pursue those questions.

3. Teacher's confidence and skills in knowing when and how to pursue children's curiosity driven questions, in a way that does not derail teaching but enhances the learning.

4. Developing teacher curiosity so that the teacher models the learning behaviours of the curious learner.

In effect, these principles underpin a pedagogy that supports a more open-ended approach to learning, where there are possibilities of many different and sometimes unforeseen outcomes. When learning is viewed as a dynamic activity, different explanation and conclusions are encouraged. This has parallels with our understanding of the nature and study of history; the enquiries which are undertaken and the oftenserendipitous ways in which historians gain new insights and knowledge. Studying history requires learners to come to terms with the complexities of the past and to question the validity of ways in which past is represented. It is curiosity which sustains historians and it is some of this curiosity which we would like to encourage amongst the children we teach.

\section{Curiosity and history}

Pickford, Garner and Jackson (2013) state that history can stimulate curiosity about the past and the connections between the past, present and future. This can provide children with a deeper understanding of themselves and others, which contributes to their sense of belonging. Through an enquiry approach to history children can develop key skills such as communication, creativity, empathy, reasoning, problem-solving and of course, curiosity. Cooper (2017) states that creativity and curiosity are dependent on the teacher's ability to 
understand and provide the opportunities for children to engage in enquiry-led learning. This involves knowing how to recognise problems, select enquiries and frame questions which are at the heart of the discipline. By its very nature, enquiry develops the use of thinking skills thereby enhancing children's learning through instilling those skills of questioning and being curious. Pickford, Garner and Jackson (2013) state that over recent years, some teachers have indicated that children are not able to think for themselves and lack the ability to be creative. However, thinking back to the climate that these teachers have been working in is it any surprise that they believe that these skills have dissipated. We would argue that the children have not changed at all; they are still asking those 'why' questions; they are still pointing and questioning; they are still enthralled with a sense of awe and wonder when faced with something new and exciting! What has changed is the culture that education is currently immersed in, with the impact of policy as described above, now having an impact on not only teachers' perceptions but their expectations of what their role is in developing curiosity. We remain hopeful that policy may again turn in favour of fostering curiosity, as modern research referred to above tells us that creativity is increasingly perceived as important in international policy and education has been cited as the vehicle to implement this. In the meantime, embedding an enquiry approach to learning can support children's higher order thinking and creativity, some of those skills that teachers believe have disappeared. In order to maximise the potential of creativity in history, there needs to be a focus on planning and preparation; this needs to be precise with an understanding of the subject key skills to be developed as well as the subject knowledge and content. Creative thinkers are able to transfer knowledge and understanding gained in one context to another. Fostering creativity through an enquiry approach in history involves providing children with opportunities to develop their confidence in decision-making. Consequently, the aim is that these skills will transfer to other subjects and we may just be able to re-engage those children who ask incessant questions because they are filled with a sense of curiosity. Bruner (1963) emphasised the importance of teachers in being able to present situations and concepts in such a way that children were able to develop their own questions that drew on their prior learning, interest and abilities. The teachers' role in this case is to scaffold and support children in asking appropriate questions and this thinking process is at the heart of history. The importance of being able to ask pertinent questions is a key skill that needs to be fostered in children, particularly in today's society where information is freely available but the source, nature and purpose of the information is not always clear or not always as intended. Bruner (1963) further stated that asking 
questions of what you are presented with is particularly sensitive in history as information is always an interpretation of the past.

Pickford, Garner and Jackson (2013) state that curiosity can be defined as a desire to know. If this is placed at the start of the learning process then teachers can be inspired and engaged in their learning. As we have established, curious children have a sense of awe and wonder and are encouraged to actively engage in exploration of the world that they inhabit. They ask questions, make interpretations and valid observations, which can be shared with others. Using history as our lens to explore the issue of questioning to develop curiosity, children need to be able to construct interpretations, or as Cooper states (2017:15), to make meaning which involves an encounter between the past and the present. History involves the construction of narratives, both by experts and learners and these narratives need to be ' analysed, questioned, explored, discussed and interpreted in relation to previous knowledge and experience, if they are able to make meaning; they are not simply explanatory'. In this way history is a sound platform for teachers to develop children as curious, questioning learners. Cooper (2017) goes on to argue that each stage of an historical enquiry involves creativity, possibility thinking and imagination. This involves knowledge of the discipline of history and the kind of questions historians ask and how they answer them. Therefore, engaging in the process of historical enquiry would involve an examination of the sources being studied in the enquiry and how the past has been constructed.

\section{Learning Theory}

It is worth stopping at this point to explore some of the discussions around learning and how learning takes place. As mentioned earlier in this paper, the principles underpinning theory and good practice, with regard to teaching and learning, are not always reflected in policy. Learning theories deal with the way people learn but defining learning is a complex process. It is not simply about the process of gaining or acquiring knowledge. Neurophysiological theories of learning, as outlined by Edelman (1993), focus on the 'biological mechanisms of learning' and discuss the issues of stimulation on the brain and memory processes. There have been a number of theorists who have attempted to define learning in psychological terms; Piaget (1950) discussed learning as a process of construction where learners are able to build their own mental structures linked to the learning environment, engaging in hands-on, experiential learning. This links to Bruner's (1963) and Cooper's (2017) ideas that teachers should provide situations where children 
can be exposed to processes that allow them to develop these skills; enquiry being one such example. Skinner (1954) defined the behaviourist theory of learning whereby learners' behaviour can be modified through the stimulus-response model. In contrast, social learning theory, as outlined by Bandura (1977) takes into account the importance of social interactions in the learning process and discusses the importance of imitation, observation, questioning and modelling. Biggs (2011) discusses learning in a much less complex way and sums up learning as 'a way of challenging the world' to enable us to 'see the world differently'. As already highlighted, this is not something that is explicitly mentioned or exploited in the current national curriculum or policy documentation. However, the real challenge is to develop curiosity and questioning and find ways to accommodate policy to allow the exploitation of curiosity, within and beyond the confines of the national curriculum. As teacher educators, the first thing we do with a new cohort of trainee teachers is to discuss themselves as learners because this understanding of self allows them to develop their understanding of children as learners, an essential skill for teachers. Therefore, the first step to creating curious children is to create curious teachers.

\section{Reflection as a tool to develop curious teachers}

As stated above, in order to create curious learners there is a need for teachers to ask questions not only about their professional practice but also to ask questions about the learning in their classrooms. We believe that in order to be an effective teacher you need to be driven by a desire for knowledge yourself through reflection, evidence based practice and research; this is a thought shared by many countries. For example, in Finland, it is standard practice for teachers to be trained to Masters level with an expectation for action research to feed into their work. Through the use of research in their classrooms teachers are able to solve problems and improve practice. In fact, teachers as researchers has a long standing tradition in education and was pioneered by Stenhouse (1975), who believed that teachers who engaged in classroom research as part of professional development and reflection were able to have a direct impact on children's learning.

A skill that is embedded into the teaching profession is that of reflection, which is an essential part of improving practice. Some teachers may do this implicitly by reflecting on a lesson during the car journey home and this will unconsciously feed into subsequent lessons, whereas others may be more explicit about their reflections through lesson evaluations, the use of reflective journals or within a community of practice. Sellars (2017, 3) states that reflection can be described as the 'deliberate, purposeful, metacognitive 
thinking and/or action in which educators engage in order to improve their professional practice'. The roots of reflective teaching stem from Dewey (1933) who believed that teachers who engage with reflective action are involved in self-appraisal and personal development that involves flexibility, rigorous analysis and social awareness.

This paper concludes with case studies that demonstrate how it is possible to foster the skills of curiosity in the current educational climate. The hope is that, despite the policy frameworks seeming to be in conflict with good practice, it is still possible to be a teacher who develops a child's sense of awe and wonder and instils a sense of curiosity.

\section{Case studies}

\section{Curiosity starts with the locality - Who was Ram Mohan Roy?}

The following case study describes ways in which Year 5 children's curiosity was stimulated through learning about the Bengali reformer Ram Mohan Roy. This was part of their school's history curriculum that aimed to develop children's understanding of significant individuals who had been linked with Bristol in the past. Focusing on significance and its importance to events of the past is a fundamental aspect of creative approaches to the teaching of history and allows children to use questioning to develop their curiosity (Partington, 1980; Counsell, 2004; Phillips, 2002). Cooper (2015, 210) reminds us that "creative approaches to history are important because they allow children to construct their own personal histories as well as the histories of others; in doing this they are starting to recognise that there is no single history and that "stories of the past can change - this values individuals, diversity and develops identity".

The school in this case study is an inner-city school, which serves diverse communities and is participating in the Heritage Schools programme funded by Historic England. The Heritage Schools programme is designed to give children a sense of pride in their locality, to understand their local heritage and how it relates to the national story. In addition, it also seeks to promote community involvement in local heritage. The National Curriculum (DfE, 2013) states that pupils should develop their understanding of British, local and world history and be able to establish clear narratives. Studying a significant individual such as Ram Mohan Roy allows children to develop a range of analytical skills using different sources of information. Evaluations of the Heritage Schools Programme to date indicate that children from schools within the programme have engaged enthusiastically with the history of their locality. 
A statue of Ram Mohan Roy stands outside Bristol Cathedral, in the centre of the city. Ram Mohan Roy looks striking in his Asiatic dress, wearing a long coat, baggy trousers and a distinctive headdress. The first area to explore is to question who he was and why he is significant. As part of their history project, Year 5 children were going to visit his tomb. Below are some of the issues that were discussed to prepare children for their visit and to help them understand the significance of Ram Mohan Roy and his connections with Bristol.

Some knowledge of the period in which Ram Mohan Roy was living was needed before introducing the children to the story of his life. Pictures of the countryside around Kolkata were shared and children were encouraged to speculate on what it might have been like to live in such places. A world map enabled children to locate Kolkata in relation to the UK and to estimate how far the city was from England and what might be the best way to travel there. Children who had visited the Indian sub-continent were able to compare time spent flying with longer journeys by sea. The map also stimulated unexpected questions and comments as one group of children were unable to find Pakistan on the map. 'I didn't know that once India and Pakistan had been one country. Why did they separate? What happened?'

The notion of trade needed to be discussed. If Britain was such a long way away, why were the British in India and what were they doing at the time? Samples of fine muslin cloth and intricate brass work were shown as examples of some of the goods which the East India Company were sending back to Britain from India.

A painting of Ram Mohan Roy was used as an introduction to his life and children asked for their views. They noticed a great deal about his outward appearance, 'rich, powerful, wealthy, princely, has a lot of money, has an Afro hairstyle, long coat, baggy trousers, curly moustache', but needed to be probed further to consider his facial expressions, 'kind, important, clever, thinking'. All children could make some response and were encouraged to justify their opinions through reference to the painting, which stimulated their interest. Children naturally had the skills of curiosity but deepening their questioning needed to be scaffolded by the teacher to move beyond simple observations and explanations. With more frequent exposure to activities that stimulate their curiosity the children would develop their higher order thinking skills. 
The next step was to ensure that children recognised why Ram Mohan Roy was significant and to know that they may not find the answers to all their questions. Uncertainty is a vital part of curiosity and creative thinking as it enables children to consider different possibilities, be open minded and use imagination (Cooper, 2015). Ram Mohan Roy believed in the existence of One Supreme God and founded the Brahmo Sabha, an influential socio-religious reform movement. Amongst the reforms which he campaigned for was the abolition of sati, a custom whereby widows were burned on their deceased husbands' funeral pyres. Ram Mohan Roy had watched his sister- in- law die at his brother's funeral and was persistent in his condemnation until the practice was finally banned in 1829. Children struggled to understand why this practice occurred and asked:

Why did they want to do that?

Didn't it hurt?

Why didn't anyone stop it?

What was the family doing about it?

Why did the wife want to do it?

These questions allowed us to explore children's historical understanding by giving them the opportunity to look at events and practices of the past through the lens of their own lives. The practice of sati seemed abhorrent to them. However, allowing them to question and consider gave them a deeper understanding of why Ram Mohan Roy was significant in his time.

Other reforms which Ram Mohan Roy supported were the introduction of women's inheritance property rights, the abolition of polygamy and child marriages. He campaigned for the freedom of the press to disseminate his views and established his own printing press, publishing journals in English, Hindi, Persian and Bengali.

The position for me as the teacher in this case study was important. I needed to position myself as someone who did not know all the answers. This allowed the children to share in my curiosity and engage in deep and open discussion. Explaining my own uncertainty to the children supported the idea that there was still more research needed to find out about his life and encouraged the children to voice their own views and to be involved in this further research in learning about him. It enabled some children to become more confident 
in making comments; some children could draw on their own 'funds of knowledge' gained from outside school to enrich the discussions. For example, one child could explain the correct pronunciation of Bengal; another explained the religious iconography of the books in bookcases from a photo of Ram Mohan Roy's sitting room and several children spoke of their experiences of being able to speak a range of languages and how they enjoyed communicating to different people in different languages.

Open and frank discussions such as this could raise sensitive issues for some class members. Teachers may find themselves faced with the decision as whether to avoid difficult subjects and conversations, but avoiding sensitive topics is not always helpful since children may want to know about issues that matter to them. Sensitive topics should not be avoided in a primary classroom. In fact Wooley (2010) suggests that any topics raised have the potential to be sensitive and therefore controversial as they are linked directly to people's values and beliefs. A pedagogy which respects children's views and finds time and space to address their interests provides one strategy for mitigating some of these concerns.

Studying the life of Ram Mohan Roy provides one example of how beginning with a local enquiry can develop into a wider network of connections which link national and global stories together. To understand his life children needed to know aspects of British history and the search for trade routes as well as what was happening in India. They also needed some appreciation of the ideas and beliefs and what mattered to people at that time. Using a historic personality in this way may also resonate with individual children who struggle to find their connections with the wider world. The example of Ram Mohan Roy illustrates how, throughout the centuries, people have made journeys for varied reasons and established connections across the globe. This work was used as a springboard to celebrate children's family origins and a large map of the world was displayed in the entrance hall, showing the journeys which many families had made to Bristol. This served to support children's sense of identity with their families' origins as well as a shared sense of belonging to the city in Bristol

\section{Curiosity- making connections with Ancient Egypt}

The following case study describes how children from a Year 2 class at Wallscourt Farm Academy, Bristol were immersed in a creative history topic on the Ancient Egyptians and 
Amelia Edwards (1831-92). As part of the Key Stage 1 history curriculum, children are expected to study a significant individual. Amelia Edwards was chosen because of her links with Bristol and the Ancient Egyptians. Amelia Edwards was a journalist, traveller, successful novelist and Egyptologist. While Amelia was born in London her travels took her far and wide before she settled in Westbury-on-Trym, Bristol. She is buried in the churchyard of St. Mary's church, Henbury, Bristol. Amelia developed a fascination with Egypt. Her friend and colleague, Andrew McCallum, discovered a previously unknown sanctuary in Egypt and for some time this bore Amelia's second name, Edwards. Amelia toured the United States of America lecturing on Egyptian exploration, as well as being a successful novelist. Looking at a topic such as the Ancient Egyptians and a significant individual such as Amelia Edwards enables children to make a connection with the past and provides a context for exploration. Following individuals from the past can help to bring the history alive, as children can find out in depth about an individual, rather than learning about the past in an abstract manner.

The topic of the Ancient Egyptians was introduced to the children in a way that would encourage them to ask questions. Children were provided with a range of hieroglyphs and a few clues, they were encouraged to solve the hieroglyphs in order to find out about their new history topic. Starting a new topic is an ideal time to foster and nurture children's interests and create an atmosphere of speculation about what the topic is about. After discovering the name of the history topic, children were encouraged to create a question wall about issues, ideas, questions that they wanted to find out during the topic; this wall was referred to many times throughout the six weeks. Roberts (2012) suggests that starting a topic in this way is essential if children are to be actively involved into an enquiry; she refers to this as 'creating a need to know'. Roberts $(2012,35)$ further suggests that teachers play a vital role in the 'creating a need to know' stage by:

- expressing uncertainty and doubt

- expressing a sense of wonder of amazement

- speculating about information rather than presenting it as fact

- expecting children to think about something for themselves

- conveying an interest in what is being studies.

Planning for creativity is hugely important. Planning therefore needs to create a degree of flexibility as it allows the teacher to follow the interests of the child without derailing the 
learning. The planning for the Ancient Egyptian topic included a challenge box to extend children's learning wherever possible. One of the questions during this topic was, 'Is it right to unwrap a mummy?'

We may immediately find that the question 'Is it right to unwrap a mummy?' is a sensitive and complex issue. However, this may not be the case for children who could see this as a simple question that would elicit a yes/no response? Raising this question could lead to a complex and challenging lesson both in terms of the sensitive content but also due to the moral discussion that would inevitably take place. Posing this question could at first imply that there is a right answer. However the teacher, Charlotte Black, was very keen to establish an environment where children were free to give their opinion, listen to others and be able to change their minds. This was first done by providing children with three different chairs that they could sit behind. These were labelled, 'Yes I think it is right to unwrap a mummy', 'No, I think it is wrong...' and 'Maybe, I am not sure'. As this was a sensitive issue Stradling et al. (1984) suggest that a possible successful strategy is to invoke debate, discussion and dialogue, in order to understand the moral issue presented here, in a respectful way. In this lesson, children were required to state their own value position first; they were asked to engage in individual thinking before sharing their opinions with others. They were then asked to move to sit behind the chair that represented their ideas about unwrapping a mummy. The physical movement here was valuable as this allowed the children to visually connect with other children with similar thoughts and for children to commit to a choice. The teacher then asked the children to share their ideas. She modelled this by using sentence starters such as: I think it is okay to unwrap a mummy because.... I don't think it is okay to unwrap a mummy because... I'm not sure if it is okay or not because...

The children commented:

'It could disturb the afterlife.'

'It could be dangerous to open a sarcophagus.'

'The people are already dead, they won't feel anything.'

'We need to learn more about the Ancient Egyptians.'

'I want to see what a mummy looks like without the bandages on.' 
'It was so long ago, I don't think it would hurt now.'

'Unwrapping will destroy the mummy.'

'The mummies would not want to be unwrapped.'

'It feels wrong.'

This links back to the thoughts about questioning being used as a platform for children to develop ideas and construct new knowledge, as well as to refer to previous knowledge and develop or change opinions. Cooper (2017) stated that this type of enquiry is an ideal vehicle to allow children to make mistakes; there are no right or wrong ways to do things in this context and no correct responses. This is a powerful tool in a system that often encourages conformity.

However, an enquiry-based approach is not without its challenges. For example, during the questioning session one child asked the teacher to give her own opinion, which left her feeling vulnerable, as she did not want her opinion to influence those of the children, recognising the power that she had in the classroom. Barton and McCully (2007) define this as a 'disclosure dilemma'. They state that there is often an assumption that teachers of history are well placed to deal with potentially controversial questions and discussions. However, this is not the case and in the situation described the teacher demonstrated a concern to share her own values with the children. This debate around teacher identity has long been a concern for teachers as it is difficult not to allow your personal self, and therefore your opinions and beliefs, to infiltrate your practice (Pollard, 2008). This impacts on the role of the teacher with regard to power and positionality. Work by Stenhouse (1975) cited in Mitchell (2017), used the term political neutrality, which implies that teachers should keep this value position hidden in the classroom and allow children to develop their own values. But how realistic is this? Recognising this, when discussing controversial issues the main role of the teacher is to ensure that a fair debate can take place, presenting a balanced approach. A lesson such as this one has a moral content and Eaude (2015) states that while there are many definitions of creativity, it will not usually be linked with Spiritual, Moral Social and Cultural Development (SMCS). However he argues that the individual nature of moral education allows children to engage with actions that have positive dispositions rather than simply being right or wrong. 
Following a discussion about children's individual thoughts on whether it is right to unwrap a mummy or not the children were then asked to work in groups to look at a range of statements that could help them make a decision. This small group activity enabled children to discuss their thoughts and ideas with other children before sharing them with the class. During the feedback session some children were more vocal than others. The sharing of the ideas prior to the whole class session was a way of making sure that all children had the opportunity to share their thoughts if they wished to. The last part of the lesson was for children to again engage in individual thinking before moving around the classroom taking a position behind the chair that represented their value position about whether it is right to unwrap a mummy. Some children had changed their minds during the lesson. This demonstrates that it takes time for children to engage with moral issues. By listening to others children are able to make informed choices based on evidence presented in the lesson and through an environment where children's voices are valued. Through dialogic pedagogy a space was created for children to rehearse their thoughts in small groups before joining in with a whole class discussion.

This lesson was followed by a visit to Bristol City Museum where an Egyptian collection was on display. This collection contained a sarcophagus which raised the question, 'is it right to open a sarcophagus?' The chance for follow up on children's classroom learning created an opportunity to deepen their understanding about the Egyptians and also to enable them to express their values and beliefs. Sometimes it can be easier to take a moral stance if you are not directly involved in the issue but in reality this can be difficult for some children. Children's natural curiosity and their need to engage in first hand, experiential learning in this way may prove challenging for some but less so much for others. While this was not a straight forward lesson to plan, as a number of considerations needed to be made, (such as teacher subject knowledge, dealing with sensitive issues, organising fieldwork and fostering an environment where curiosity and creativity are maintained), the outcomes for the children have proved to be invaluable in terms of, not only their increased understanding of historical knowledge, but also the development of questioning skills and therefore curiosity. The children had been provided with a number of experiences; the opportunity to engage in critical discussion, and to be able to make informed decisions and to consider how these decision may change over time, when presented with new information. Cooper $(2015,207)$ states that creating curiosity in this way has involved "passing control to the learner, valuing learners' innovative contributions, ownership and 
control and being a co-participant in the learning" which are vital characteristics of a creative curriculum.

\section{Conclusion}

In this article we have illustrated how curiosity can be fostered in history by using significant people and events as a platform. History is an ideal vehicle to unlock children's curiosity as it involves an attraction to the unknown but also allows children to share their own interests and ideas (Engel, 2011). The key factor that will allow children's curiosity to be developed lies with the teacher. Teachers have the power to accommodate policy making to create the space in their classrooms to foster creativity. Practitioners engaged in reflective practice should be able to develop what Claxton (2008) calls an epistemic culture that fosters an understanding of the importance of learning as a process and not an end goal, which in turn creates the right climate for developing questioning, reflection and consequently curiosity.

Acknowledgement: Thanks to Wallscourt Farm Academy, Penelope Harnett and Easton C.E. Academy for their involvement in this research.

\section{References}

Ball, S. 1997. Policy sociology and critical social research: a personal review of recent education policy and policy research. British Educational Research Journal 23 no. 3: 257-274

Ball, S. (2008) The Education Debate. London: The Policy Press

Bandura, A. 1977. Social Learning Theory, Englewood Cliffs, New Jersey: Prentice Hall.

Barton, K.C. and A. W. McCulley. 2007. Teaching controversial issues...where controversial issues really matter. Teaching History 127:12-19.

Beijaard, D., P.C., Meijer, and N. Verloop. 2003. Reconsidering research on teachers' professional identity. Teaching and Teacher Education 20, no. 2:107-128.

Biggs, J. 2011. Teaching for Quality Learning at University. Berkshire: Open University Press.

Bruner, J. 1963. The Process of Education. Cambridge, MA: Harvard University Press. 
Bullock, A. and H. Thomas, 1997. Schools at the centre? A study of decentralisation. London: Routledge.

Claxton, G. 2008. What's the point of School? Rediscovering the heart of education. Oxford: One world publications.

Coe. R., Aloisi,C., Higgins,S. and Elliot Major, L. (2014) What makes great teaching? Review of the underpinning research. Available online at https://www.suttontrust.com/wp-content/uploads/2014/10/What-Makes-GreatTeaching-REPORT.pdf [Accessed on 20.8.17]

Cooper. H. 2015. Teaching History Creatively. London: Routledge.

Cooper, H. 2017. Why must teaching history be creative? in Cooper, H. (2017) 2nd Edition. Teaching History Creatively. London: Routledge.

Counsell, C. 2004. Looking though a Josephine-Butler-shaped window: focusing pupils' thinking on historical significance. Teaching History 114: 30-33. London: The Historical Association.

Day, C. 2002. School reform and transitions to teacher professionalism and identity. International Journal of Education. 37 no.2: 677-692.

Dewey, J. 1933. How Adults Think: A restatement of the relation of reflective thinking to the educative process. New York: D C Heath and Co.

Department for Education (DfE) 2013. National Curriculum for Key stage 1 and 2. London: Department for Education

Department for Education (DFE) 2017. The Early Years Foundation Stage. London: HMSO

Edelman, G. 1993. Bright Air, Brilliant Fire, On the Matter of the Mind. New York: Basic Books.

Engel, S. 2011. Children's Need to Know: Curiosity in Schools. Harvard Educational Review 81 No. 4:625-45.

Eaude, T. 2015. New perspectives on Young Children's Moral Education. London: Bloomsbury.

Giddens, A. 1991. Modernity and Self-Identity: self and society in the late modern age, Cambridge: Polity Press.

Hargreaves, A. 1994. Changing teachers; changing times: teachers' work and culture in the postmodern age. London: Cassell.

Helsby, G. 1995. Teachers' construction of professionalism in England in the 1990's. Journal of education for teaching: international research and pedagogy. 15: 41-61.

Her Majesty's Stationery Office (HMSO) (1988) Education Reform Act 1988, Chapter 40, Part 1, Chapter 1. 
Jeffrey, B and Woods, P. (2002) The reconstruction of primary teachers' identities. British Journal of Sociology of Education 23(1) pp89-106

Kagan, J. 1972. Motives and development. Journal of Personality and Social Psychology. Vol 22, no.1: 51-66.

Mitchell, D. 2017. 'Handling controversial issues in geography' in M. Jones, and D. Lambert, 2017. Debates in Geography. $2^{\text {nd }}$ Edition. Oxon: Routledge

Moss, G. 2017. Reimagining the future in the light of the past. Literacy Vol. 51 no.2: 5664.

O'Connor, K. 2008. You choose to care: teachers, emotions and professional identity, Teaching and Teacher Education 24 no.1:117-126.

Partington, G. 1980. The idea of an historical education. Slough: NFER.

Phillips, R. 2002. 'Historical Significance- the Forgotten “key element”?' $11-18$. Teaching History No.106: 14-19. London: The Historical Association

Piaget, J. 1954. The Construction of Reality in the Child. New York: Basic Books.

Piaget, J. 1950. The Psychology of Intelligence. London: Routledge \& Kegan Paul.

Pickford, T., Garner, W. and Jackson, E. 2013. Primary Humanities: Learning Through Enquiry. London: Sage.

Pollard, A. 2008. Reflective teaching in schools. London: Bloomsbury Academic

Roberts, M. 2012. Geography through enquiry: Approaches to teaching and learning in the Secondary School. Sheffield : Geographical Association.

Sellars, M. 2017. Reflective Practice for Teachers. 2nd Edition. London: Sage.

Singh, P. Heimans, S. and Glasswell, K. 2014. Policy enactment, Policy and

Performativity: ontological politics and researching Australian National Partnership

Policies, Journal of Educational Policy 29 (6) 826-44.

Skinner, B.F. 1954. The Science of Learning and the Art of Teaching. Harvard Educational Review 24:88-97.

Standards and Testing Agency 2018-19. Teacher Assessment Frameworks at the end of Key Stage 1

https://www.gov.uk/government/uploads/system/uploads/attachment_data/file/683448 /Teacher_assessment_frameworks_at_the_end_of_key_stage_1_for_use_from the 20 18_to_2019_academic_year_onwards.pdf

Standards and Testing Agency 2018-19. National Curriculum Assessments, Teacher Assessment Frameworks at the end of key Stage 2.

https://www.gov.uk/government/uploads/system/uploads/attachment_data/file/647107 /2017_to_2018_teacher_assessment_frameworks_at_the_end_of_key_stage_2_PDFA. pdf. 
Stenhouse, L. 1975. An Introduction to Curriculum Research and Development. London: Heinemann Educational Books.

Stradling, R., Noctor, M. Baines, B. 1984. Teaching Controversial Issues. Essex: Key set compositions.

Tizard, B. and M. Hughes, 1984. Young Children Learning. Cambridge MA: Harvard University Press.

Von Stumm, S., B. Hell, and T. Chamorro-Premuzic. 2011. The hungry mind: Intellectual curiosity is the third pillar of academic performance. Perspectives on Psychological Science. Vol. 6 no.6: 574 -588.

Whitty, G. 2002. Making Sense of Education Policy. London: Sage.

Wilkins, C. 2011. Professionalism and the post-performative teacher: new teachers reflect on autonomy and accountability in the English schools system. Professional Development in Education 37:3:389-409.

Woods, P. and Jeffrey, B. 2002 The Reconstruction of Primary Teachers' Identities, British Journal of the Sociology of Education, 23.1: 89-106.

Wooley, R. 2010. Tackling controversial issues in the primary school: Facing life's challenges with your learners. London: Routledge. 